Research Concept

\title{
Combinational approach of energy management for sustainable food and crop storage facilities: A research concept
}

\author{
Mohammad Nur-E-Alam 1,*, Soyed Mohiuddin Ahmed 2, Mohammad Nasirul Hoque ${ }^{3}$, Mohammad Khairul Bash- \\ er ${ }^{4}$ and Narottam Das ${ }^{5,6}$ \\ 1 Electron Science Research Institute, Edith Cowan University, WA 6027, Australia; E-mail: \\ m.nur-e-alam@ecu.edu.au, nurealam840@gmail.com (M. N.-E-A.) \\ 2 School of Pharmacy \& Life Science, Jiujiang University; Jiujiang, Jiangxi, P.R. China; E-mail: \\ mohiuddinppqc@yahoo.com (S. M. A.) \\ 3 Department of Physics, University of Chittagong, Chattogram 4331, Bangladesh; E-mail: nasirul@cu.ac.bd \\ (M. N. H.) \\ 4 Institute of Electronics, AERE, Bangladesh Atomic Energy Commission, Dhaka-1349, Bangladesh; E-mail: \\ khairulcu@gmail.com (M. K. B.) \\ 5 School of Engineering and Technology, Central Queensland University Australia, Melbourne, VIC 3000, \\ Australia; E-mail: n.das@cqu.edu.au (N. D.) \\ ${ }^{6}$ Centre for Intelligent Systems, School of Engineering and Technology, Central Queensland University, Bris- \\ bane, QLD 4000, Australia.
}

\begin{abstract}
This research project focuses on the optimization of the hybrid energy system together with the assistance of thin-film coatings aiming to achieve self-sustainable food and crop storage facilities which will run effectively with its own generated energy. An infrastructure will be designed and constructed that will comprise a hybrid power generation system accompanied by thin-film coated semitransparent and non-transparent construction materials for energy saving. Thin-film low emissivity (Low-E) type coatings will assist the transparent or semitransparent construction materials to reflect most of the infrared (IR-mostly heat) and UV spectra of sunlight without interrupting the visible spectrum and will lead to saving energy consumption by reducing the heat and lighting during day time
\end{abstract}

Keywords: coating; food and crop; hybrid energy; storage facility; sustainability.

\section{Introduction}

The present world is running on 16 trillion watts of power per year which is mostly generated from fossil fuels. Among all users the residential and commercial consumers in the building sector consume one-fifth of the world's total delivered energy. In order to reduce the carbon dioxide $\left(\mathrm{CO}_{2}\right)$ emissions as well as achieving an improved green globe, the uses of renewable energy sources are well known. However, using only renewable energy sources will not be the best solution for a fossil-fuel-free sustainable green world. It seems that the combination of simultaneous energy-generation and energy-saving approach can help to redesign the pathways to build a new-sustainable world. Scientists, physicists, engineers, and other researchers together with a large number of the world's population should work together to save the planet. This research proposal combines two distinct research areas for achieving simultaneously energy generation and energy savings for sustainable off-grid production of food and storage. The proposed approach is to combine optimized hybrid power generation systems with coating materials applied to transparent/semitransparent roofing sheets which can control the solar spectral radiation into the storage facility and can control the heat out of the storage facility. Since this is a research concept only and it is in an early stage, this paper cannot present any quantitative and qualitative or estimated data. We aim to deliver a comprehensive insight into our research project. 


\section{Background and Motivation}

Grain losses are a fact of life for all farmers throughout the process of grain production. This paper is concerned with grain loss post-harvest during storage and how this can be mitigated. Post-harvest grain loss is one of the major causes of food insecurity for small-holder farmers in developing countries. In most cases, the smallholder farmers either in developing countries or in the rural farming and cultivation areas use conventional grain storage structures using various effective storage processes. Hermetic storage systems are an effective means of storing grain efficiently, minimizing grain loss without the use of chemicals. By reducing grain storage losses and maintaining grain quality through the use of a hermetically sealed system, food insecurity for small scale producers will be reduced as profits will increase. Besides all other costs, these kinds of storage facilities have a massive budget for energy consumption to regulate and maintain adequate temperature, relative humidity, ventilation, and air circulation [1-4]. In recent years, energy: cost efficiency has become one of the key factors for sustainable food and crop storage facility, that stimulate scientist's enthusiasm to introduce more off-grid, self-sustainable energy-harvesting, and saving facilities.

Among the commercial consumers, the farming and food security section is one of the main candidates that usage energy 24 hours in a day and all the year-round as well. To cap the carbon dioxide concentration in the air at $450 \mathrm{ppm}$, it is necessary to reduce the energy harvest from burning fossil fuels up to 3 TW within the next 25 years and produce the rest of the required energy from renewable sources. Besides this, all the traditional industrial renewable energy generation resources including photovoltaic (PV) solar farms using huge land areas, impacting land-use efficiency [5-15]. Recently, a significant number of research works have been projected to build an optimized hybrid power generation system that can be a potentially cost-effective solution to reduce the budget of electricity generation in developing countries and/or remote areas. Recent research reports show that a hybrid power generation system can predominantly encompass more than one renewable energy generation systems thus can lead developing an integrated and sustainable approach to build a pathway towards a fossil-fuel-independent infrastructure towards the green global demand [16-28]. Alternatively, thin-film coatings mainly the low-emissivity (Low-E) type coatings can reduce either the heating-related or the cooling-related or both (limited cases) electric energy usage in buildings. The low-E coatings are typically structured as dielectric/metal/dielectric (DMD) multilayer thin films deposited by various methods, promotes the strong and very wide-band reflection of thermal infrared wavelengths. Recently energy harvesting PV glass windows (contain thin-film coating) capable of on-site energy generation simultaneous with the functionality of tailoring the incident sunlight spectrum required for different crops that improve production yields, can be useful for the design and building of innovative and cost-effective greenhouses for horticultural industries [29-44].

In this research project, an advanced sustainable energy saving, and energy generation food and crop storage facility would be developed to compensate R \& D efforts by reducing energy consumption and/or provide on-site energy-generation storage facilities, and eventually, that would be the key economic factor for the research area of modern agricultural biotechnology and food safety. Figure 1 shows a graphical presentation of a modelled storage facility that is proposed and outlined in this project proposal. 


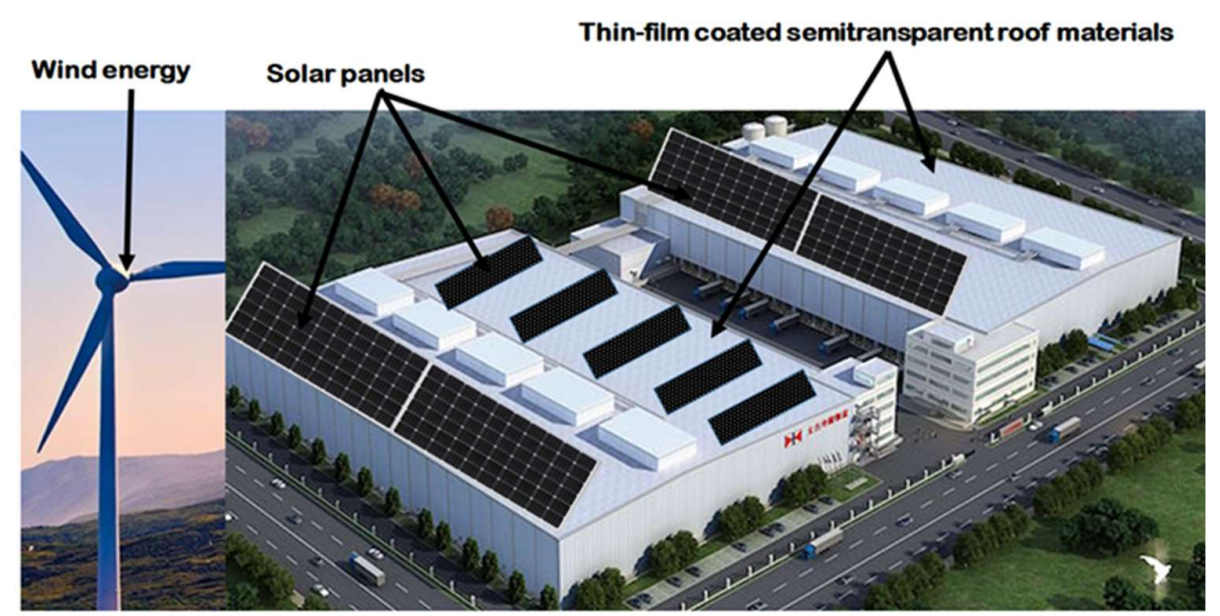

(a)

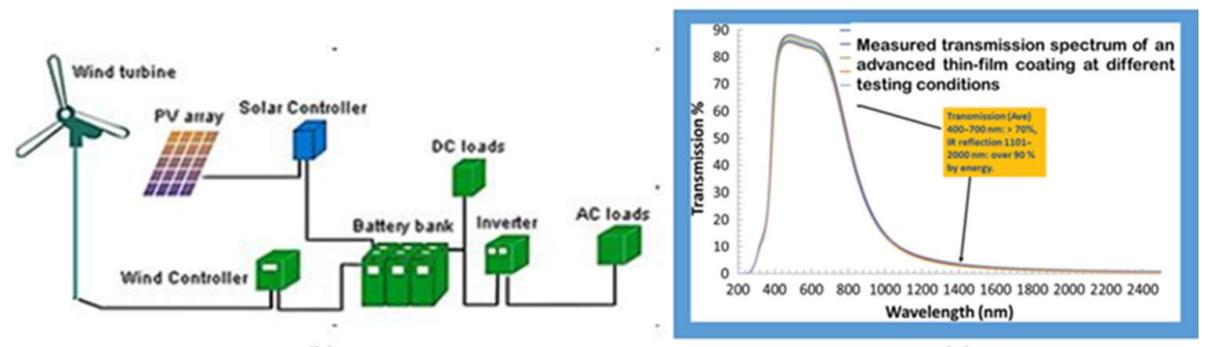

(b)

(c)

Figure 1. (a) An example of proposed infrastructure that containing more than one power generating system together with thin-film coated roof materials, (b) A hybrid power generation/collection system diagram, and (c) An optical transmission of power through the thin-film coatings deposited on the glass substrates, which shows that most of the UV and IR bandwidth of the Sun spectrum (mainly heat) can be filtered by this type of coating structures without interrupting the visible light. Note the advances of materials and their physical processing systems allow depositing large-scale size spectrally selective thin-film coatings on any substrate.

\section{Approach and Methodology}

This research will be based on the optimization of energy savings by thin-film coatings, and renewable energy generation systems for reducing the cost of energy and minimize the greenhouse gases. The optimization process required some input parameters, such as meteorological data, load use of the particular located area, system configuration, energy system model, etc. This research methodology assists to minimize the total system cost and reduced the production of $\mathrm{CO}_{2}$. For modeling of the component, the Hybrid Optimization of Multiple Energy Resources (HOMER) software will be used for simulation. The design and configuration of solar, wind, and other power generation systems for the hybrid system includes.

1) Select and Modelling of PV Arrays System,

2) Select, Modelling, and optimization of other power sources like diesel,

3) Study the effective battery bank for storage,

4) Study the voltage mismatch and effect of shading effect on the losses of PV systems,

5) Study the cost-efficiency in terms of power generation and savings, and

6) Practical demonstration of the mini-scale cold-storage facility. 


\section{Significance and Innovation of the proposed research concept}

This proposed research project will be a novel, revolutionary, and highly promising R\&D direction in modern materials science and photonics, to help to develop and testing an innovative and practical thin-film optical coating applicable to save heating and cooling related energy together with the successful development of an optimized hybrid energy generation system. The innovations in energy materials science and engineering will also be beneficial to the construction industry. This research project includes the following specific objectives:

1) Achieving an improved understanding of materials scientific properties relevant to the design and fabrication of customized multiple low-emissivity (low-E) coating type with precisely spectrally-controlled features.

2) Developing small-scale new highly durable optical coatings following environmental (heat and humidity) exposure test.

3) Optimization of a stand-alone hybrid system using the HOMER software.

4) Developing and investigating the viability of multiple renewable energy generation processes and development of an optimized hybrid system with minimum power losses due to mismatch of high voltage and current.

5) Minimize the cost of consumed energy and reduce the pollution commission which is mainly responsible for the greenhouse effect by using a hybrid (solar/wind/diesel) system.

6) Minimize the system cost of stand-alone renewable sources by using a hybrid system with the help of mathematical components that are required for modeling.

7) Optimization of solar, wind, and diesel with storage systems using a genetic algorithm (GA) method.

The broader significance of this research project includes (i) promotion of national research in nanomaterials related technology (ii) advanced understanding of applied science in cutting-edge renewable energy technologies, and (iii) generation of knowledge and intellectual property that will bring benefits to the researchers, industries, and communities.

\subsection{Expected outcomes of this research work}

The expected outcomes of this research will advance the knowledge and practice in the design of advanced coating assisted savings and hybrid models of renewable energy generation system for cost-effective, stand-alone, and off-grid construction facilities for food and crops storages. Particularly, the research will enhance knowledge through:

1) The study and characterization of a new hybrid energy generation system.

2) Study of energy savings with the assistance of thin-film based coatings from the economic point of view.

3) Practically cost-effective, energy-generating and energy-saving storage (small size) will be designed, constructed, tested, and validated for the future use in food and crop industries as well as small and medium businesses.

4) The results of these R\&D activities are expected to have a sustainable impact extending well beyond the current expansive food and crop storage facilities.

In addition, significant innovations are expected in food industries due to the incremental demand for energy-savings towards obtaining net-zero facilities in the future. The research results can be circulated through: (i) high-impact articles submitted to international journals and conferences, (ii) general-interest on articles and media releases, (iii) scientific articles presented in national and international seminars and conferences, and (iv) interaction and engagement with industries. Moreover, this research project will open the possibility of applying for many governments and industry-funded research grants. Furthermore, the development of these new technologies will create a new mar- 
ket and will offer more job opportunities, requiring personnel for business management, sales and marketing, administration, logistics, and manufacturing.

\subsection{Project timeline and expectations}

The expected outcomes of this proposed research project are divided into several parts (considering the project time about two years) as elaborated below:

The first phase (P1): A rigorous literature review and gather up to date information about existing and new renewable energy systems and advanced coatings (i.e., Low-E type) will be conducted to find out the real issues, i.e., the research gap that needs to be addressed or be upgraded for the benefit of the existing renewable systems, utilities and consumers.

The second phase (P2): This period will be projected for comprehensive modelling and optimization of hybrid power generation systems, together with the designing of thin-film coatings (spectrally-selective). The simulation will be conducted using hybrid energy system modelling using the HOMER software, and also modelling the coating will be conducted using commercially available software such as OptiLayer Pro and others. Then, the model-based simulation and experimental results will be analysed and processed for documentation and research publications in high impact reputed journals.

The third phase (P3): The outcome of this phase is less rigidly defined as in the previous Parts 1 and 2. In this part, investigation of detail the performance and analyses will be followed for daily/weekly (average) updated data (i.e., power generation and saving).

The fourth phase (P4): The outcome of this period is research publications that are less rigidly defined as in the previous Parts. In this part, it is expected to publish the research outputs in peer-reviewed high-quality journals (Q1) and leading national and international conferences, workshops, and media releases (both locally and nationally).

\subsection{Benefit and Communication results of this research}

The research project will create the opportunity to establish and build capabilities to conduct cutting-edge intelligent and smart energy system researches, simulation, and building toward a more specialized research capability in smart food storage facilities. It is expected that this research will be enriched through international partnership collaborations with overseas institutions and scholarly publications. Also, this work will contribute to a large knowledge base and specialized research group for renewable energy and sustainability of Off-grid systems which can offer expertise to industry as the renewable resources worldwide. This project will enable us to accomplish the following major expectations in the future including (i) Development of Off-grid Hybrid Power Generation and Saving Infrastructure, and (ii) Building National Research Capacity and Priorities.

\section{Conclusions}

This section is not mandatory but can be added to the manuscript if the discussion is unusually long or complex. This project will deliver a model for advanced crop storage systems that will enable the generation of energy and the saving of energy in food storage facilities and so assist remote area farmers and small/medium business holders. Possible future research publications are as follows:

* Design and optimization of off-grid stand-alone hybrid power generation systems in conjunction with the use of coated materials for buildings.

* Feasibility study of optimized off-grid energy engineering for food storage facilities in rural or coastal areas. 
- Case studies of hybrid power generation systems in conjunction with solar controlled coated building materials for the practical demonstration through pilot projects.

* Cost efficiency and payback period relationship studies for the practical implementation of an optimized hybrid power generation system in conjunction with modern coated building materials.

So far we have conducted a slightly different research work (simulation based) based on this concept and reported in a high impact journal "Sustainability" [45]. In the reported article, we demonstrated the design and optimization of a thin-film coating-assisted, self-sustainable, energy-efficient and cost-effective off-grid hybrid (photovoltaic-battery-generator) power system suitable for advanced cattle farming in Bangladesh which is a new and forward-looking approach for sustainable development of the livestock sector. Based on the simulation results, we recommended that energy engineering together with the advanced building material coatings can be the model for modern farming in any rural areas, and can help to reduce the carbon emission footprint as well [45]. However, the practical demonstration of this work is an on-going research program within our group depending on the availability of sufficient research funds.

Author Contributions: Conceptualization, M.N-E-A.; methodology M.N-E-A., M.N.H; software, M.N-E-A., and M.N.H.; validation, M.N-E-A., M.N.H., S.M.A., M.K.B., and N.D.; investigation, M.N-E-A.; resources, M.N-E-A., and M.N.H.; writing-original draft preparation, M.N-E-A.; writing-review and editing, M.N-E-A., M.N.H., S.M.A., M.K.B., and N.D.; visualization, M.N-E-A., M.N.H., S.M.A., and M.K.B.; supervision, M.N-E-A.; project administration, M.N-E-A. All authors have read and agreed to the published version of the manuscript.

Funding: Please add: This research received no external funding.

Institutional Review Board Statement: Not applicable.

Informed Consent Statement: Not applicable.

Conflicts of Interest: The authors declare no conflict of interest.

\section{References}

1. A. Manandhar, P. Milindi, A. Shah, An Overview of the Post-Harvest Grain Storage Practices of Smallholder Farmers in Developing Countries. Agriculture. 8 (2018) 57.

2. D. Kumar, P. Kalita, Reducing postharvest losses during storage of grain crops to strengthen food security in developing countries. Foods. 6(1) (2017) 8.

3. H. Pekmez, Cereal storage techniques: A review. Journal of Agricultural Science and Technology B. 6 (2016) 67-71.

4. On-Farm-Cold-Storage.:https://fruit.triforce.cals.wisc.edu/wp-content/uploads/sites/36/2017/02/On-Farm-Cold-Storage.pdf (accessed on 3 September 2020)

5. International Energy Outlook 2010, a report by the Office of Integrated Analysis and Forecasting, U.S. Energy Information Administration, U.S. Department of Energy (July 2010), available from http://www.eia.doe.gov/oiaf/ieo/pdf/0484(2010).pdf.

6. B. Sterling, "Renewistan," published online at http://www.wired.com/beyond_the_beyond/ 2009/01/renewistan/ (sighted in April 2011).

7. K. Kaygusuz, Energy for sustainable development: A case of developing countries. Renewable and Sustainable Energy Reviews. 16(2012), 1116-1126.10.1016/ j.rser.2011.11.013

8. R. R. Hernandez, M. K. Hoffacker, M. L. Murphy-Mariscal, G. C. Wu, M. F. Allen, Solar energy development impacts on land cover change and protected areas. PNAS, 112 (44) (2015) 13579-13584; first published October 19, 2015 https://doi.org/10.1073/ pnas.1517656112

9. R. R. Hernandez, M. K. Hoffacker, C. B. Field, Land-Use Efficiency of Big Solar. Environmental Science \& Technology. 2013.

10. S. Ong, C. Campbell, P. Denholm, R. Margolis, G. Heath, Land-Use Requirements for Solar Power Plants in the United States. National Renewable Energy Laboratory (NREL) at www.nrel.gov/publications.

11. R. R. Hernandez, S. B. Easter, M. L. Murphy-Mariscal, F. T. Maestre, M. Tavassoli, E. B. Allen, C. W. Barrows, J. Belnap, R. Ochoa-Hueso, S. Ravi, M. F. Allen, Environmental impacts of utility-scale solar energy. Renewable and Sustainable Energy Reviews, 29, (2014) 766-779. 
12. T. Guerin, Using agricultural land for utility-scale photovoltaic solar electricity generation. Australian Farm Institute's quarterly newsletter, 14(3) (2017).

13. C. P. Castillo, F. Batista e Silva, C. Lavalle, An assessment of the regional potential for solar power generation in EU-28. Energy Policy, 88 (2016) 86-99.

14. Can we expand solar power dramatically without damaging protected lands? https://theconversation.com/can-we-expand-solar-power-dramatically-without-damaging-protected-lands-49429 (Accessed on 14 Sep 2020).

15. E. H. Adeh, S. P. Good, M. Calaf, C. W. Higgins, Solar PV Power Potential is Greatest Over Croplands. Scientific Reports volume 9, Article number: 11442 (2019)

16. A. Lopez-Rey, S. Campinez-Romero, R. Gil-Ortego, A. Colmenar-Santos, Evaluation of Supply-Demand Adaptation of Photovoltaic-Wind Hybrid Plants Integrated into an Urban Environment. Energies, 12(2019) 1780.

17. K. Patel, N. Das, M. M. K. Khan, Optimization of hybrid solar, wind and diesel energy systems from economic point of view, In Proc. of the 29th Australasian Universities Power Engineering Conference 2019 (AUPEC 2019), Nov. 26-29, 2019, Momi Bay , Fiji.

18. R. Dufo-López, J. L. Bernal-Agustín, F. Mendoza, Design and economical analysis of hybrid PV-wind systems connected to the grid for the intermittent production of hydrogen. Energy Policy, 37(2009) 3082-3095. http://dx.doi.org/10.1016/j.enpol.2009.03.059

19. A. A. Prasad, R. A. Taylor, M. Kay, Assessment of solar and wind resource synergy in Australia. Appl. Energy, 190(2017) 354367.

20. M. Egido, E. Lorenzo, The sizing of standalone PV-system: A review and a proposed new method. Solar Energy Materials and Solar Cells, 26(1992) 51-69. http://dx.doi.org/10.1016/ 0927-0248(92)90125-9

21. F. J. Santos-Alamillos, D. Pozo-Vázquez, J. A. Ruiz-Arias, V. Lara-Fanego, J. Tovar-Pescador, Analysis of Spatiotemporal Balancing between Wind and Solar Energy Resources in the Southern Iberian Peninsula. J. Appl. Meteorol. Climatol. 2012, 51, 20052024.

22. J. Widen, Correlations Between Large-Scale Solar and Wind Power in a Future Scenario for Sweden. IEEE Trans. Sustain. Energy 2011, 2, 177-184.

23. H. Zhang, Y. Cao, Y. Zhang, V. Terzija, Quantitative synergy assessment of regional wind-solar energy resources based on MERRA reanalysis data. Appl. Energy 2018, 216, 172-182.

24. B. N. Prashanth, R. Pramod, G. B. Veeresh Kumar, Design and Development of Hybrid Wind and Solar Energy System for Power Generation, Materialstoday: Proceedings, $5(5,2)(2018)$ 11415-11422.

25. Y. Sawle, S. C. Gupta, A. K. Bohre, PV-wind hybrid system: A review with case study, J. Cogent Engineering, 3(1) (2016) 1189305.

26. M. A. Elhadidy, S. M. Shaahid, Parametric study of hybrid (wind+solar+diesel) power generating systems. Renewable Energy, 21 (2000) 129-139.

27. M. A. Elhadidy, S. M. Shaahid, Promoting applications of hybrid (wind+photovoltaic + diesel+battery) power systems in hot regions. Renewable Energy, 29(2004) 517-528. http://dx.doi.org/10.1016/j.renene.2003.08.001

28. A. A. Solomon, D. M. Kammen, D. Callaway, Investigating the impact of wind-solar complementarities on energy storage requirement and the corresponding supply reliability criteria. Appl. Energy 2016, 168, 130-145.

29. G. Ding and C. Clavero (March 8th 2017). Silver-Based Low-Emissivity Coating Technology for Energy- Saving Window Applications, Modern Technologies for Creating the Thin-film Systems and Coatings, Nikolay N. Nikitenkov, IntechOpen, DOI: 10.5772/67085.

Available

from: https://www.intechopen.com/books/modern-technologies-for-creating-the-thin-film-systems-and-coatings/silver-based-low-e missivity-coating-technology-for-energy-saving-window-applications.

30. R. Saidur, M. M. Hasan, A. S. M. A. Haseeb and H. H. Masjuki, 2008. Energy-Efficient Optical Coating for Flat Glass. Journal of Applied Sciences, 8: 1883-1890.

31. M. Nur-E-Alam, M. Vasiliev, K. Alameh, Dielectric/Metal/Dielectric (DMD) multilayers: Growth and stability of ultra-thin metal layers for transparent heat regulation (THR). Chapter 4, Energy Saving Coating Materials: Design, Process, Implementation and Recent Developments; Edited by G. K. Dalapati and M. Sharma, Elsevier: Amsterdam, The Netherlands, 2020.

32. M. Nur-E-Alam, M. M. Rahman, M. K. Basher, M. Vasiliev, K. Alameh, Optical and chromaticity properties of metal-dielectric composite-based multilayer thin-film structures prepared by RF magnetron sputtering. Coatings, 2020, 10 (3), 251.

33. M. Vasiliev, K. Alameh and M. Nur-E-Alam, "Spectrally-selective energy-harvesting solar windows for public infrastructure applications," Appl. Sci. 2018, 8, 849; doi:10.3390/ app8060849.

34. Q. Xue, R. Xia, C. J. Brabec, H. L. Yip, Recent advances in semi-transparent polymer and perovskite solar cells for power generating window applications, Energy Environ. Sci., 2018,11, 1688-1709.

35. J. JONES, From Energy Sink to Energy Efficient: A Walk Through Window Technologies, https://www.architectmagazine.com/technology/from-energy-sink-to-energy-efficient-a-walk-through-window-technologies_ o (Accessed on 15 Sep. 20 20).

36. Reflective and low-E coated glass, https:/www.efficientenergychoices.com.au/files/ Lowe\%20Glazing\%20NGP_Section_03.pdf (Accessed on 15 September 2020) 
37. O. Bouvard, M. Lanini, L. Burnier, R. Witte, B. Cuttat, A. Salvade, A. Schuler, Structured transparent low emissivity coatings with high microwave transmission. Appl. Phys. A (2017) 123:66 DOI 10.1007/s00339-016-0701-8.

38. Low-cost, highly transparent flexible low enable electrochromic windows with increased energy savings, https://www.osti.gov/servlets/purl/1262341. (Acceesed on 15 September 2020).

39. M. Vasiliev, M. Nur-E-Alam, K. Alameh, Transparent heat regulation materials and coatings: Present status challenges and opportunity. Chapter 3, Energy Saving Coating Materials: Design, Process, Implementation and Recent Developments; Edited by G. K. Dalapati and M. Sharma, Elsevier: Amsterdam, The Netherlands, 2020.

40. S. Amirkhani, A. Bahadori-Jahromi, A. Mylona, P. Godfrey, D. Cook, Impact of Low-E Window Films on Energy Consumption and $\mathrm{CO}_{2}$ Emissions of an Existing UK Hotel Building. Sustainability 2019, 11(16), 4265; https://doi.org/10.3390/su11164265

41. Good Agricultural Practices for greenhouse vegetable crops, http://www.fao.org/3/a-i3284e.pdf (Accessed on 15 September 2020)

42. S. Hemming, F. L. K. Kempkes and J. Janse, New Greenhouse Concept with High Insulating Double Glass and New Climate Control Strategies - Modelling and First Results from a Cucumber Experiment. https://core.ac.uk/download/pdf/29227243.pdf (Accessed on 14 September 2020).

43. M. Nur-E-Alam, M. Vasiliev, J. A. Thomas, A step forward towards advanced and self-sustainable greenhouse agriculture. DOI: 10.32545/encyclopedia202004.0028.v4.

44. J. A. Thomas, M. Vasiliev, M. Nur-E-Alam, K. Alameh, Investigation of the optimum illumination spectrum for maximizing the energy savings and yield of Lactuca sativa, L. in glass greenhouses. Sustainability, 12 (19) 20203740.

45. M. Nur-E-Alam, M. N. Haque, M. Ahmed, M. K. Basar, N. Das, Energy Engineering Approach for Rural Areas Cattle Farmers in Bangladesh to Reduce COVID-19 Impact on Food Safety, Sustainability, 2020, 12(20), 8609. 